\title{
Industrial applications of phase transfer catalysis (PTC): past, present and future
}

\author{
H. H. Freedman \\ Dow Chemical USA, Central Research New England Laboratory, \\ Wayland, MA 01778 USA

\begin{abstract}
The advantages of PTC for industrial processes are discussed and recent progress in catalysts, methodology and applications is critically reviewed. Various trends and new applications of commercial interest are emphasized.
\end{abstract}

\section{INTRODUCTION}

No new catalytic method in organic synthesis has been so rapidly adopted and applied so extensively as PTC. Since its introduction by the pioneering work of Makosza, of Brandstrom and of Starks in 1965-71, publications in which PTC is the focus (Fig. 1) have increased at a remarkable pace with some slackening in 1985.

Similarly, the number of different applications for PTC has increased to the point where a "compendium" published in 1979 (ref. 1) lists over 65 different types of organic compounds (from acetals to urethanes) which can advantageously be synthesized by PTC techniques. In fact, PTC has become one of the most useful weapons in the arsenal of the organic chemist and, more often than not, is the method of choice for processes in which one of the reactants is an anionic species, either added as an alkali salt or generated in situ by a base.

Not only does PTC promote the reaction between reagents which are mutually immiscible (i.e., sodium salts and alkyl halides) but it also, at least for batch processes, offers a number of important process advantages, some of which are listed in Table 1.

These factors contribute to overall process efficiency in terms of process simplification, equipment size, product and solvent purity and ease of recovery, as well as cost saving by the elimination of the need for the expensive solvents, anhydrous strong bases and oxidants needed as the alternative to PTC. The rapidly growing PTC patent literature attests to the industrial interest; even if we assume that on 1 y $10-20 \%$ of these patents are actually practiced, then its industrial impact is currently significant and its potential even more so.

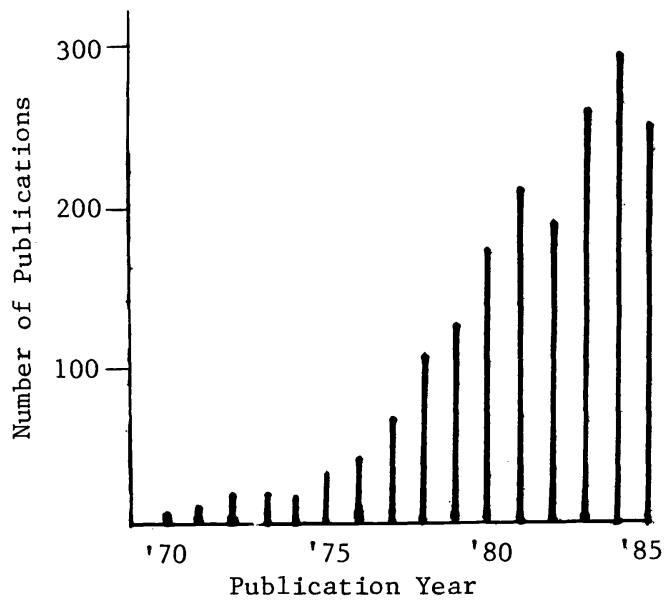

Fig. 1 Growth of PTC Publications, 1970-85
TABLE 1. Advantages of PTC for Industrial Processes

Increased rates of reaction

Increased product specificity

Lower energy requirements

Use of inexpensive, non-toxic, recoverable solvents or use of liquid reactant as solvent

Commercially available, inexpensive catalysts Use of inexpensive bases for anion generation Use of inexpensive oxidants 
The original Stark's mechanism (ref. 2), generalized for the $\mathrm{SN}_{2}$ displacement of $\mathrm{Cl}$ by a nucleophile $X^{-}$, catalyzed by a quaternary ammonium salt $\left(Q^{+}\right)$is given in (1).

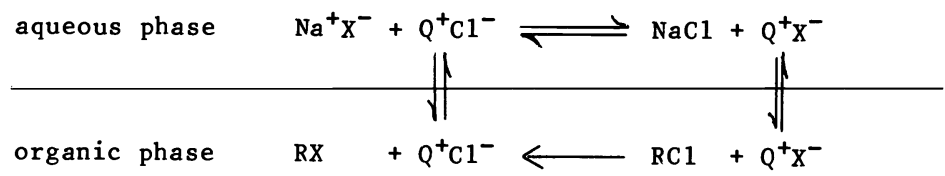

This has stood the test of time and it is clear that the reaction takes place in the organic phase and that the rate is primarily determined by the extractability of the anionic reactant by the PT catalyst. There remain areas of controversy as to the exact role of the catalyst when the anionic nucleophile is generated in situ by the action of concentrated base on weak acids. However, mechanistic considerations are not our primary interest here; rather, this review will attempt to assess the role of PTC in chemical industry where, for better or worse, primary consideration is given not to mechanism but to utility and economics. The literature has previously been comprehensively reviewed through ca 1979 (refs. 1,3,4) and developments of the past five years will be considered here.

\section{CATALYSTS}

The choice of which PTC catalyst to use - quaternary ammonium $\left(Q^{+}\right)$, phosphonium ( $\left.Q P^{+}\right)$, crown ether, such as 18-crown-6 $(18-\mathrm{C}-6)$ or a polyethylene glycol (PEG), will depend on a number of process factors. These include reaction type, solvent, temperature, base strength and ease of catalyst recovery and removal. If these factors are not decisive, then catalyst cost will determine the choice. Table 2 lists most of the common, commercially available in bulk PT catalysts and estimates the cost for 5 mol \% of each.

TABLE 2. Commercially Available PT Catalysts

\begin{tabular}{|c|c|c|c|c|}
\hline Catalyst & Source & Approx. M.W. & Cost $/ 1 \mathrm{~b}$ & Cost of $5 \mathrm{~mol} \mathrm{\%}$ \\
\hline PEG $-600^{a}$ & Union Carbide & 600 & 0.60 & $\$ 0.04$ \\
\hline TBMAC ${ }^{\mathrm{b}}$ & Ethyl Corp. & 236 & 2.15 & 0.07 \\
\hline BTEACC & RSA Corp. & 228 & 3.50 & 0.09 \\
\hline Aliquot $-336^{d}$ & Henke 1 Corp. & 400 & 2.00 & 0.09 \\
\hline Adogen-464d & Sherex Chem. Corp. & 400 & 2.00 & 0.09 \\
\hline TBAB ${ }^{e}$ & Hexe1 Corp. & 340 & 5.50 & 0.21 \\
\hline TBPC $\mathrm{f}$ & RSA Corp. & 340 & 35.00 & 1.30 \\
\hline $18-c-6$ & Parish Chem. Corp. & 264 & 225.00 & 6.50 \\
\hline \multicolumn{2}{|c|}{$\begin{array}{l}\text { a Polyethyleneglycol } \\
\text { c Benzyltriethylammonium chloride } \\
\text { e Tetrabutylammonium bisulphate }\end{array}$} & \multicolumn{3}{|c|}{$\begin{array}{l}\text { b Tributylmethylammonium chloride ( } 75 \% \text { soln.) } \\
\text { d Tricaprylmethylammonium chloride } \\
\text { f Tetrabutylphosphonium chloride (tech., } 85 \%)\end{array}$} \\
\hline
\end{tabular}

Both the least and most expensive catalysts in Table 2 are polyethers which presumably function similarly as cation complexers. Where the $\mathrm{OH}$ groups of the PEG are detrimental (i.e., for oxidations) their mono- and di-alkylated derivatives are available and can be substituted. Recent work suggests that the PEG's can replace the expensive 18-c-6. Examples where the former equalled or outperformed the latter include synthesis of 1-cyanooctane (ref. 5), esterification (ref. 6), phenol alkylation (ref. 7), matrix immobilization (ref. 8) and alkaline hydrolysis of poly(methyl methacrylate)(ref. 9). PEG's have been termed "the poor chemist's crown" (ref. 9a) and the applications listed in Table 3 testify to their increasing importance as PT catalysts.

With two exceptions, the $Q^{+} s$ remain as the $P T$ catalyst of choice; $Q^{+1}$ s are inherently thermally unstable and decompose at temperatures over $90^{\circ}$ and are also decomposed by bases stronger than $60 \%$ sodium hydroxide. Under these conditions the catalysts of choice are the $\mathrm{QP}^{+}$'s or polyethers, both of which have greater stability. However, if the reaction is reasonably fast, $Q^{+}$may still be preferred, even if replenishment is necessary. 
TABLE 3. Use of PEG's as PT Catalysts

\begin{tabular}{|c|c|c|c|c|}
\hline $\begin{array}{l}\text { Reaction } \\
\text { or Product }\end{array}$ & Catalyst & $\begin{array}{l}\text { Approx. } \\
\text { 非 of exs. }\end{array}$ & $\begin{array}{c}\text { Average } \\
\text { yie1d (\%) }\end{array}$ & Reference \\
\hline Triarylphosphates & PEG-400 & 6 & $90-96$ & 10 \\
\hline Ester hydrolys is & PEG $-400-4000$ & 1 & 100 & 11 \\
\hline Phenol alkylation & PEG-400-4000 & 3 & 80 & 11 \\
\hline $\begin{array}{l}\text { Oxidation of } \\
\text { c-acids }\end{array}$ & various PEG's & 6 & 50 & 12 \\
\hline Horner-Emmons rxn & various PEG's & - & - & 13 \\
\hline $\mathrm{N}$-alkylation & PEG/dialk PEG & 5 & "excellent" & 14 \\
\hline Ethers & dialk. PEG's & 5 & 90 & 15 \\
\hline $\begin{array}{c}\text { A1koxylation of } \\
\text { halobenzenes }\end{array}$ & PEG -6000 & 8 & 65 & 16 \\
\hline Phenytoin synth & PEG-600 & 1 & 90 & 17 \\
\hline Reduction of $\mathrm{C}=0$ & PEG/dialk.PEG & 10 & 80 & 18 \\
\hline Dehydroha log. & various PEG's & 8 & 80 & 19 \\
\hline $\begin{array}{l}\text { Nitration with } \\
\text { nitrite }\end{array}$ & PEG -600 & 1 & - & 20 \\
\hline $\begin{array}{l}\text { Williamson ether } \\
\text { synth. }\end{array}$ & DiBu-PEG-600 & 5 & 90 & 21 \\
\hline Aldol rxn & PEG -600 & - & 50 & 22 \\
\hline $\begin{array}{l}\mathrm{N} \text {-protection } \\
\text { of Amino Acids }\end{array}$ & PEG-600 & 4 & - & 23 \\
\hline Esterification & $\begin{array}{l}\text { PEG }-400 \\
\left(\text { on } \mathrm{Al}_{2} \mathrm{O}_{3} / \mathrm{SiO}_{2}\right)\end{array}$ & 2 & 50 & 24 \\
\hline $\begin{array}{l}\text { Oxidation with } \\
\text { NaOCl }\end{array}$ & PEG -350 & 2 & 30 & 24 \\
\hline
\end{tabular}

Where catalyst cost is not critical, $T B A B$, first introduced by Brandstrom, remains the most popular. A recent economic evaluation of $Q^{+' s}$ in industrial applications (ref. 25 ) concludes that at a price of $\$ 4,500 /$ ton, TBABr is practical even for higher priced commodities. A final decision will depend on the cost of catalyst recovery, usually by aqueous extraction of the organic layer and re-extraction of the $Q^{+}$with an appropriate solvent. For TBABr (and perhaps other $Q^{+' s}$ as well) a novel process using aqueous extraction and $\mathrm{pH}$ adjustment yielded an organic layer containing $92 \% \mathrm{Q}^{+}$which was recycled at least 10 times with no yield loss (ref. 26). Removing the last traces of $Q^{+}$, usually by ion-exchange, can be difficult and expensive but is often required for drugs and $Q^{+}$-sensitive products. Most of this technology is propietary and little literature is available.

New PT catalysts continue to be reported (1-4) which are claimed to have superior thermal stability.

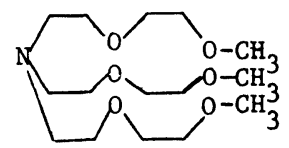

$\underline{1}$

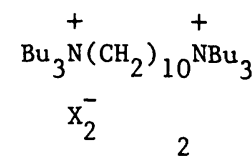

$\underline{2}$

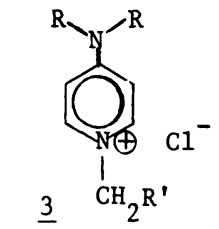

$R, R^{\prime}=$ various alkyl's

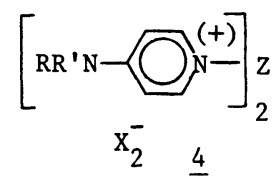

$R, R^{\prime}=a 1 k y l s$ $Z=a .1 k y l e n e, P E G$

TDA-1 (1), recently introduced on a limited commercial basis by Rhone-Poulenc, is an open chain cryptate analog which, according to its discover, is effective for aromatic substitutions at $130^{\circ}$ and also exerts a synergistic effect in the Ullman reaction (ref. 27). The General Electric Co. has patented two di-Q ${ }^{+1}$ s $(\underline{2} \& 4 \underline{4})$, both of which are claimed to be useful for the synthesis of the precursor compounds for polyether imides (refs, 28, 29), production of one of which (U1tem) is expected to reach 12 million pounds in the near future (ref. 30). The dimethylaminopyridinium Q's (3), of which 4 is a variant, have been described in detail by Brunelle (ref. 31) who states that these are effective PT catalysts for aromatic nucleophilic displacements, are up to 100 times more stable than $\mathrm{TBABr}$ to phenoxide and can function at $200^{\circ}$. This is certainly a notable advance. 


\section{METHODOLOGY}

\section{Techniques}

The original premise that the solid-liquid PTC technique is limited to catalysis by crown ethers has long been shown to be incorrect and that $Q^{+}$catalysis is equally applicable. A recent example reports the esterification of the dry sodium salt of 14 different aromatic carboxylates with alkyl bromides catalyzed by TBABr in $80-100 \%$ yield (ref. 32). Similarly, solid-liquid PTC is preferred for SNAr reaction of activated aryl halides with phenoxide (ref. 33). Tundo has developed still another technique, - gas-liquid PTC, in which a gaseous alkyl halide is continuously reacted at temperatures up to $170^{\circ}$ with various nucleophiles catalyzed by a $\mathrm{QP}^{+}$salt deposited on a solid matrix. This method was used to prepare alkylated malonates (refs. 34, 35), carboxylate esters (ref. 36), transesterification products (ref. 37) and alkenes by the Wittig reaction (ref. 38). Using $\mathrm{QP}^{+}$catalyst at $200^{\circ}$, a melt synthesis of diaryl sulfides was accomplished (ref. 39). Finally, using solid-liquid PTC with TBABr at high dilution, $\omega$-bromocarboxylates were converted to macrolides $(n=7-17)$ in excellent yields (ref. 40).

\section{Supported catalysts}

When originally introduced as "triphase catalysis" (ref. 41) polymer-supported PTC showed promise for solving two important PTC deficiencies: lowering catalyst cost by recycling and eliminating residual catalyst in the product. This promise has not been realized and we are not aware of any industrial applications of supported PTC. The reasons for this can be inferred from the extensive investigations of Ford (ref. 42,43) which have recently been reviewed. As a catalyst, $Q^{+}$immobilization on a polystyrene matrix currently suffers from diffusion limitations, gradual loss of activity and mechanical unstability. Recent work has focused on polymer supported PEG's. Applications and supports include phenate alkylation at $250^{\circ}$ (ref. 44 ), block copolymers (ref. 45), immobilization on metal surfaces (ref. 46) and on alumina or silica (ref. 47).

\section{GENERAL APPLICATIONS}

\section{Polymers}

The polymer chemists have enthusiastically adopted PTC and continue to utilize it for various polymer applications including monomer synthesis, polymerization, polymer modification and, in a recent development, free radical catalyst activation. The literature is voluminous and has been reviewed for polymer synthesis (ref. 48), and modification (ref. 49), and for polymerization, including condensation (ref. 50), anionic (ref. 51) and free radical (ref. 52). Here we can only touch on recent significant developments.

PTC is particularly well adapted for condensation polymerization and, in fact, was being used for the production of polycarbonates from bis-phenate salts and phosgene even before it was recognized as a PTC example. It is probable that this is the major PTC polymer application today even though the recent literature ignores polycarbonates in favor of other polymers prepared by condensation polymerization of bisphenol-A in aqueous base with organic solutions of various dihalo compounds. These include the production of polyethers by reaction with 1,4-dichloro-2-butene (ref. 53), dibromomethane (ref. 54) and p-xylylene dichloride (ref. 55) and of polyesters from isophthaloyl chloride (ref. 56). Percek has reached paper \#14 in his studies on aromatic polyethers and derived block copolymers and is currently exploring their thermotropic properties (ref. 57).

PTC continues to be productive for the chemical modification of polymers, an area summarized by Frechet (ref. 58). Chloromethylated polystyrene continues to be the most studied substrate (ref. 59). Among the many modifications currently reported are etherifications (ref. 60), Wittig-type reactions (ref. 61), reactions with phthalimide (ref. 62) and with malononitrile (ref. 63). other polymer reactions include poly(methylmethacrylate) hydrolysis (ref. 64), dehydrohalogenation of poly(vinylchloride) and its copolymers (ref. 65), cycloproponation of butadiene-based rubber (ref. 66), nucleophilic substitution on poly(1-chloro-2-epoxypropane)(ref. 67), poly(vinylfluoride) dehydrohalogenation (ref. 68) and grafting on poly(vinylchloride)(ref. 69). This 1 ist is by no means complete but is indicative of the activity in this area.

The most significant recent application of PTC to polymer science is in free radical polymerization catalysis as discovered and developed by Rasmussen (ref. 70). The use of $18-C-6$ or a $Q^{+}$solubilizes potassium peroxydisulfate, or similar radical-forming 
salts, in organic solvents and greatly increases their ability to initiate free radical polymerizations of various acrylic monomers. The patented process (ref. 71) has been scaled up to at least 2000 gal. batches in the pilot plant (ref. 72). Though mechanistic problems remain (ref. 73) PTC-promoted free radical initiation is an important contribution.

\section{Aromatic substitution}

Recent work has greatly extended the use of PTC for substitution of aromatic halides, usually activated chloride. Table 4 lists some representative examples. In many of these reactions a temperature above the normal decomposition point of the $Q^{+}$catalyst is employed. An exception to this is the use of a $Q P^{+}$catalyst (ref. 77a) and the the rmally stable catalyst, TDA (ref. 79).

TABLE 4. Aromatic Substitution Reactions

\begin{tabular}{|c|c|c|c|}
\hline Reaction & \# of Exs. & Approx. Yield (\%) & Reference \\
\hline $\begin{array}{l}\text { 2,6-dihalopyridines } \overrightarrow{\text { 2-hydroxy-6-halopyridines }} \\
\text { (n) }\end{array}$ & 9 & 95 & 74 \\
\hline$\underset{\mathrm{m} \text {-nitroanisole }}{\mathrm{m} \text {-dinitrobenzene }} \rightarrow$ & 1 & 83 & 75 \\
\hline $\begin{array}{l}\text { 2,5-dichloro-nitrobenzene } \rightarrow \\
\text { 2-hydroxy-5-chloro-nitro- } \\
\text { benzene }\end{array}$ & 1 & 92 & 76 \\
\hline $\begin{array}{l}\text { poly-chlorobenzenes } \rightarrow \\
\text { alky1 ary1 sulfides }\end{array}$ & $\sim 8$ & 80 & $77,77 a$ \\
\hline $\begin{array}{l}\text { dinitrochlorobenzenes } \vec{\longrightarrow} \\
\quad \text { nitrochlorobenzonitriles }\end{array}$ & - & - & 78 \\
\hline $\begin{array}{l}\text { 4-chloronitrobenzene } \longrightarrow \\
\text { 4-subst. nitrobenzene }\end{array}$ & 4 & 85 & 79 \\
\hline
\end{tabular}

\section{Dehydrohalogenation}

With few exceptions, PTC has not been particularly successful for base catalyzed dehydrohalogenation, particularly with respect to selectivity in the production of geometrical and/or positional isomers. At least part of the problem can be attributed to the low extractability of hydroxide. This can lead to a rate determining, diffusion controlled process with unexpected complications involving catalyst, agitation and solvent (ref. 80). This is documented by the work of Rostomyan, et. a1., who has reached paper $\$ 12$ in the series "Dehydrohalogenation of Organic Compounds using Phase Transfer Catalysis" (ref. 81), and reports that vinyl chloride is obtained from dichloroethane by $\mathrm{KOH} / \mathrm{Q}^{+}$dehydrochlorination in $99 \%$ yield in benzene or toluene, but only in $50 \%$ yield in ethylbenzene. Lack of selectivity is evident in the formation of a mixture of cis- and trans-, 1- and 2-chloropropene from KOH/ polyether dehydrohalogenation of 1,2-dichloropropane (ref. 83) as well as the carefully defined conditions needed for the optimal preparation of 2-chloro-1,3-butadiene (ref. 82). other recent examples include the synthesis of phenylacetylenes (ref. 84 ), 1-pheny1-2-chloroacetylene (ref. 85), $\alpha, \beta$-unsaturated acids (ref. 86) and ketones (ref. 87), p-chloromethyl styrene (ref. 88), methy1 $\alpha$-(bromomethy1)acrylate (ref. 89) and the dehydrohalogenation of poly(vinylchloride) (ref. 90).

\section{Oxidations}

Inorganic oxidants in organic media under PT conditions has been and continues to be an important synthetic tool. The most commonly used oxidant has been potassium permanganate whose properties and utility have been reviewed (ref. 91). For pharmaceuticals this expensive reagent may be the oxidant of choice as, for example, in the synthesis of fusaric acid (ref. 92). However, $10 \%$ aqueous hypochlorite, generally supplied as "swimming pool bleach" can, in many cases, act as an effective, inexpensive substitute. A number of new applications using hypochlorite have been reported since its introduction by Lee and Freedman (ref. 93). These include oxidation of hydroquinone and catechols (ref. 94), 4-naphthoquinone (ref. 95), glycolic to glyoxylic esters (ref. 96), acids from aldehydes (ref. 97) and thioether oxidation (ref. 98). The hypochlorite oxidation of benzyl alcohol (ref. 93) continues to be investigated, both as to the effect of conditions on product selectivity (ref. 99) and the use of solid phase catalysts (ref. 100). 
Epoxidation by oxidation with $\mathrm{H}_{2} \mathrm{O}_{2}$ is a fertile new PTC area. This new catalytic 2-phase system requires both tungstate and phosphate (or arsenate) as the epoxidizing catalyst and $a \mathrm{Q}^{+}$or $\mathrm{QP}^{+}$for solubilizing the latter in the organic solvent. when all three components are present, epoxidation using dilute $(<10 \%) \mathrm{H}_{2} \mathrm{O}_{2}$ becomes extremely efficient and both terminal and internal olefins are epoxidized with $80-90 \%$ selectivity on both olefin and $\mathrm{H}_{2} \mathrm{O}_{2}$ (ref. 101). this process requires the unsually low $\mathrm{pH}$ of $<2$ for maximum efficiency but apparently is useful even for acid sensitive epoxides. The question of whether or not at this low $\mathrm{pH}$ this process is compatible with the starks mechanism remains to be answered, but there can be no doubt that epoxide production using dilute peroxide has economic potential.

\section{Organometallic}

This has been reviewed in 1981 (ref. 101) and in 1984 (ref. 102) by Alper, one of the major contributors to the use of PTC for carbonylation of halides, hydroformylations and reduction of olefins, nucleophilic substitution and isomerizations. Recent PTC work with potential for industrial application include iron pentacarbonyl catalyzed formations of carboxylic acid derivatives (ref. 103), alkoxycarbonylation of conjugated dienes (ref. 104) and dehydrohalogenation of organic halides (ref. 105). Lastly, solid phase PT catalysis, consisting of PEG's covalently bonded to a metal oxide surface, has been used for the carboxymethylation of benzyl bromide to methyl phenylacetate and propylene oxide to methyl 3-hydroxybutyrate (ref. 106).

\section{Polyhydroxy compounds}

Alkylation of sugars and carbohydrates has been an active area. PTC technique has been successfully used for the esterification of hexitols (ref. 107), derivatization of D-arabinofuranose (ref. 108), stereoselective $\alpha$-glucosylation (ref. 109), synthesis of tetra-0-acety $1-\beta-D-g 1$ ucopyranosyl and galactopyranosyl sulfides (ref. 110), acetylated ary $1-\beta-D-g 1$ uco and galactolpyranosides (ref. 111) and 0-alkylation of carboxymethylcellulose (ref. 112). The industrially important alkylation of cellulose has been accomplished with benzyl and ethyl chloride as well as chloroacetic acid and acrylonitrile in the presence of $\mathrm{Me}_{4} \mathrm{~N}^{+} \mathrm{Cl}^{-}$(ref. 113), a $\mathrm{Q}^{+}$not normally known for its efficiency in PT processes. We can speculate that stability rather than lipophilicity is important here.

\section{Chiral PTC}

The use of optically resolved catalysts for the direct synthesis of enantiomerically pure compounds remains one of the major "holy grails" of the organic chemist. It would seem that PTC is particularly well adapted to this problem and that catalytic quantities of optically pure $\mathrm{Q}^{+}, \mathrm{QP}^{+}$or crown ethers, if present in a chirally discriminating tight ion pair in the transition state, would yield pure enantiomeric products either from prochiral substrates or by kinetic resolution of racemic substrates. The realization of this goal has proven to be difficult and the bulk of the early attempts, using mainly $Q^{+' s}$ derived from natural product alkaloids, gave dissappointing1y sma11 ee's.

A recent breakthrough has demonstrated the need for carefully controlling the many reaction variables. Dolling and his co-workers (ref. 114) have successfully demonstrated the first efficient chiral PTC alkylation, the conversion of 5 to 6 in $95 \%$ yield and $92 \%$ ee using as catalyst $8-\mathrm{R}, 9-\mathrm{S}, \mathrm{N}-(\mathrm{p}-\mathrm{trif1uoromethylbenzy} 1)$ cinchonium bromide, 7. Besides the catalyst, the reaction variables which affected the ee and required optimization include the solvent, substrate, base and alkyl halide concentration, agitation rate and temperature.

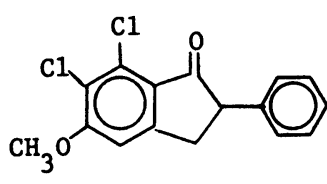

$\underline{5}$

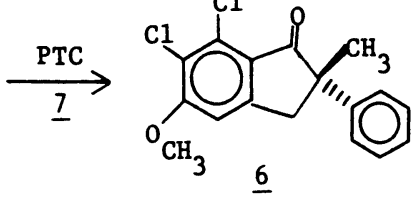

$\underline{6}$

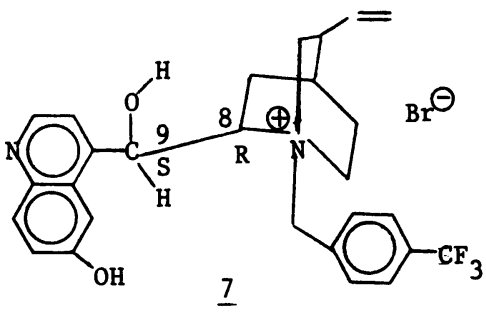

An interesting example of kinetic resolution by PTC has recently appeared (ref. 115). Using resolved $\mathrm{Et}_{3} \mathrm{~N}^{+} \mathrm{CH}_{2} \mathrm{CH}(\mathrm{Me}) \mathrm{EtBr}-$ as catalyst, $\alpha$-methylbenzy1 alcohol was methylated in $50 \% \mathrm{NaOH} /$ pentane to yield $84 \%$ of the $\mathrm{R}(+)$ methyl ether with $48 \% \mathrm{ee}$, while the recovered alcohol had $40 \%$ ee. 
A new type of chiral catalyst has been prepared by quaternization of resolved 2,2'-bisbromomethy1-1,1-binaphthyl with (-)ephedrine and gave $37 \%$ ee in a PTC epoxidation (ref. 116). Considering that even minor changes in the catalyst strongly influences optical purity (ref. 117), it is difficult to assess the potential of new catalysts which afford products with only moderate ee.

It is even more difficult to understand the enthusiastic acceptance of polymersupported PTC for chiral reactions. Considering that these supported catalysts have been markedly inferior as PT catalysts in general, it is remarkable that a 1984 review (ref. 118) lists over 60 references for supported chiral PTC. Though little of promise has appeared, the optimism remains and recent work covers the use of chiral functional polymers. This includes esterification using poly(L-isopropylethyleneimine)(ref. 119), copolymers of (-)methylmethacrylate with vinyl compounds for ketone reduction (ref. 120) and polystyrene resins with protected galactose functions (ref. 121). In no case was a practical optical yield obtained.

\section{GENERAL INDUSTRIAL APPLICATIONS}

\section{Pharmaceutical}

From its inception, PTC has been adopted by the pharmaceutical industry. This is certainly not unexpected considering the importance of improved synthetic methodology for the production of their high value products. This topic has been reviewed (ref. 122) with emphasis on Beecham's and Astra's processes for synthetic penicillins and for drugs derived by $0-$ and $\mathrm{N}$-alkylation of various heterocycles. These remain as important commercial processes while additional PTC applications to drug production continue to be introduced. Table 5 lists some of these processes, most of which are related to we11 established PTC reactions.

TABLE 5. Pharmaceutical-Related PTC Processes

\section{Product}

Vincamines

Morphine

Azapins

Amrinone

Chloropromazine

2-H-Chromene

Phenoxyalkanoic Acids

Erythromycin A

Prostatrienoic Acids

Penicillins

Pyrimidine diones

Deazadeoxyinosine

Alkoxypyridazinones

Benzodiazapin-2-ones

\section{Reaction}

A1kylation

Ring-annelation

$\mathrm{N}$-alkylation

Cyclocondensation

N-alkylation

0-alkylation

Dichlorocarbene addition

Transesterification

Condensation

Esterification

Alkylation

Glycosylation

Alkoxylation

$\mathrm{N}$-arylation
Reference

123

124

125

126

127

128

129

130

131

132

133

134

135

136

Unnatural amino acids have potential bioactivity and 0'Donne11's (ref. 136) method via PTC alkylation of the Schiff's base (Eq. 2) presents a novel route to these compounds. His recent work includes the synthesis of 1-aminocyclopropane-1-carboxylic

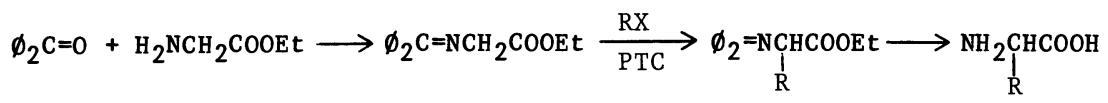

acid, cycloleucine and 2,6-diaminopimelic acid (ref. 137) as well as the use of potassium carbonate in refluxing acetonitrile with a $Q^{+}$as an alternative to his previous use of hydroxide-methylene chloride/Q $Q^{+}$(ref. 138). This method has been adapted and modified to include a PT catalyzed Michael addition for the production of glutamic acid (ref. 139) and for the $\alpha$-hydroxylation of amines by reaction of the Schiff's base with an aldehyde (ref. 140).

Maximizing pharmacological activity calls for extensive derivatization, often by $N$, 0 , $S$ and C-alkylation for which PT catalysis is particularly well suited. Three 
examples, of the many newly available, are given here. Thirty-five derivatives of the pyridazinone (ㅇ) were prepared in good yields by $\mathrm{TBABr}$ catalyzed N-alkylation

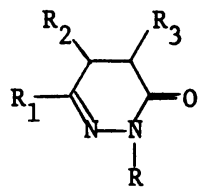

으

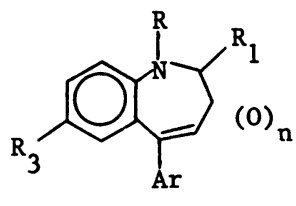

$\underline{9}$

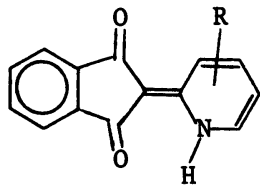

$\underline{10}$

(ref. 141) while the benzodiazapin $\underline{9}$ was similarly $\mathrm{N}$-alkylated in yields $90 \%$ using BTEAC (ref. 142). The N-alkylation of the pyridyl-indon-1,3-dione 10 is a particularly dramatic case; whereas mixtures of $\mathrm{N}$ - and $\mathrm{C}-\mathrm{alkylated}$ products were obtained in DMF with sodium hydride, only regioselective $\mathrm{N}$-alkylated products were obtained using PTC in aqueous hydroxide-methylene chloride. (ref. 143).

\section{Pesticides}

The production of synthetic organic pesticides is a multi-billion dollar industry in which PTC continues to make significant contributions. The synthetic pyrethroids, including fenvalerate $(\underline{11})$, cypermethrin $(\underline{12})$ and their various analogs are

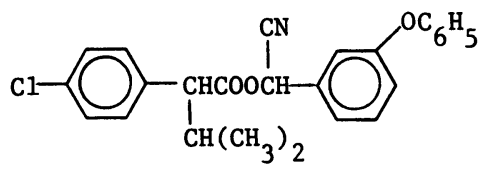

$\underline{11}$<smiles>CC1(C)C(C=C(Cl)Cl)C1C(=O)OC(C#N)c1cccc(O)c1</smiles>

$\underline{12}$

commercially produced utilizing PTC methods for the C-alkylation of the former type and esterification of the latter. Details are available in the voluminous patent literature issued to Sumimoto, She11, ICI, etc., of which we cite only two (ref. 144). Other recent applications include stereospecific s-alkylation of phenylphosphonothiolates (ref. 145), herbicidal 2-halo-acetamides (ref. 146), insecticidal 1,5-bisary1-1,4-pentadiene-3-ones (ref. 147) and substitutions of aromatic or heterocyclic 2-acetonitriles as pesticide intermediates (ref. 148).

\section{General}

The maturation of PTC has led to an increase in industrially oriented applications in diverse areas, some quite unexpected. In this section we document a number of these.

One of the problems associated with the PT process is that a mole of salt is generated for each mole of product. This often leads to a costly waste disposal problem inasmuch as the resulting salt stream is invariably contaminated with trace amounts of organics. Renga has developed (ref. 149) a novel salt-free process for the production of aryl ethers by using methyl trichloroacetate as a proton sponge in the presence of catalytic amounts of potassium carbonate and 18-C-6 (Eq. 3). Over 15 aryl ethers

$$
\mathrm{ArOH}+\mathrm{RX} \frac{\mathrm{CCl}_{3} \mathrm{COOCH}_{3}}{\mathrm{~K}_{2} \mathrm{CO}_{3}, \begin{array}{c}
18-\mathrm{C}-6 \\
150^{\circ}
\end{array}} \mathrm{ArOR}+\mathrm{CHCl}_{3}+\mathrm{CH}_{3} \mathrm{X}+\mathrm{CO}_{2}
$$

have been prepared in yields of $72-91 \%$ and an analogous process for the methylation of carboxylic acids is available (ref. 150). In both processes the relatively high temperature needed makes the use of a $Q^{+}$impractical, but it is likely that PEG's can substitute for the $18-\mathrm{C}-6$.

Epichlorohydrin (epi), a commodity chemical, has inspired a number of PTC applications leading to the reactive intermediates, glycidyl ethers and esters. A sampling of recent work includes the reaction of epi with bisphenol-A (ref. 151), aminophenols (ref. 152), alcohols (ref. 152a) and sodium stearate (ref. 153). 
Finally, we have chosen some unusual PTC processes with commercial implications. Benzotrichlorides are obtained from benzal or benzylchlorides by reactions with perchloroalkanes; i.e., 3-methylbenzal chloride in refluxing carbon tetrachloride with $50 \%$ sodium hydroxide and a $Q^{+}$affords $93 \%$ of 3 -methylbenzotrichloride (ref. 154). Scrap rubber can be converted to an improved product by cleaving polysulfide cross-links by treating the hydrocarbon swollen rubber particles with hydroxide $/ Q^{+}$ (ref. 155). PCB's can be removed from transformer oils by reaction with alkyl mercaptans in a toluenefotassium hydroxide $/ Q^{+}$system (ref. 156). Similarly PCB's can be reacted with $P E G^{\prime}$ 's/hydroxide at $75-120^{\circ}$; presumably the PEG functions both as reactant and catalyst (ref, 157).

Phenolic products can be removed from aqueous alkali waste streams by contacting the stream in a continuous reactor-settler with a toluene solution of benzyl chloride and a PT catalyst. The 0-benzylated phenol can be recovered and the phenol content lowered to $45 \mathrm{ppm}$ (ref. 158). Heating 4-chlorobenzonitrile with sodium sulfide/QP without a solvent at $150^{\circ}$ yields $\left(4-\mathrm{CNC}_{6} \mathrm{H}_{4}\right){ }_{2} \mathrm{~S}$ (ref. 159) and by now it should come as no surprise that even coal can be 0 -alkylated to form ethers and esters by standard PTC methods (ref, 160).

\section{THE FUTURE FOR PTC}

In the past, each successful PTC application stimulated research which in turn led to additional applications and improved processes. There is every reason to believe that this trend will continue, at least for the near future. This growth is being further accelerated by the chemical industry's shift away from commodities, in which PTC has historically played a minor role, to the "specialties" for which PTC is particularly well adopted. Further, the inherent convenience of the PTC method has been made even more so; all the common and many of the more esoteric catalysts are commercially available, the former in drum or carload quantities. The PTC literature has been organized, digested and alphabetically arranged in the numerous journal reviews, chapters and books. It remains only for the chemist to adapt it toward the application of interest.

Rather than try to predict where future progress in PTC lies, we list those areas which are currently of potential commercial importance but are not yet economically viable. It is reasonable to expect future PTC research to concentrate on:

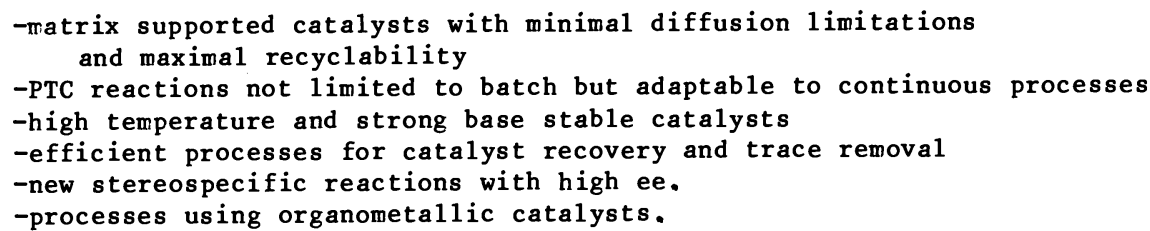

It will be of interest to reassess the progress in PTC five years from now.

\section{REFERENCES}

1. W. E. Keller, Compendium of Phase-Transfer Reactions and Related Synthetic Methods, Fluka, Switzerland (1979).

2. C. M. Starks, J.Am. Chem. Soc., 93, 195 (1971).

3. C. M. Starks and C. Liotta, Phase Transfer Catalysis, Academic Press, NY (1978).

4. E. V. and S. S. Dehmlow, Phase Transfer Catalysis, Verlag Chemie (1980).

W. P. Weber and G. W. Gokel, Phase Transfer Catalysis in Organic Synthesis, Springer-Verlag, Berlin (1978).

5. G. W. Goke1, P. M. Goli and, R. A. Schultz, J. Org. Chem., 48, 2837 (1983).

6. J. Harris, et, al., Polym. Sci. Tech., 24, 371 (1984).

0. Filippova, et. al, , Chem. Abstr., 101, 22686J (1984).

7. J. Hradil and F. Svec, Polym.Bul1, 10, 14 (1983).

8. J. M. Harris, et, a1., J. Org, Chem, 47, 4789 (1982).

9. A, S. Gozdz, Makromo1. Chem, Rapid Comm., 2, 443 (1981).

9a, D, Bal asubramanian and B, Chandani, J. Chem, Ed, , 60, 77 (1983).

10. V. K, Krishnakumar, Synth. Commun, 14, 189 (1984).

11. S. Slaoui, et, al,, Tetrahedr, Lett., 23, 1681 (1982).

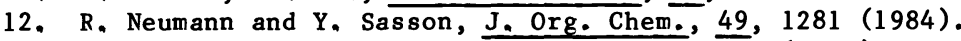

13. N. Huang, et.al., Chem. Abstr., 99, 157904Q, (1983).

14. K. Sukata, Bul1. Chem. Soc. Jpn., 56, 280 (1983).

15. JP $82,586,37$ (1980), Chem. Abstr., 97, 109687H (1980).

16. R. Neumann and Y. Sasson, Tetrahed., $\overline{39}, 2427$ (1983).

17. J. H. Poupaert, et. al., Bull. Soc. Chim. Belg., 93, 493 (1984).

18. B. G. Zupancic and M. Koka1j, Synth. Commun,, 12, 881 (1982). 
19. Y. Kimura and S. L. Regen, J. Org. Chem., 48, 195 (1983).

20. K. Matsunaga and T. Yamashita, Chem. Abstr. 94, 31679Y (1980).

21. K. Sukata, Chem. Abstr., 95, 80037S (1981).

22. B. Zupancic and M. Koka1j. Synth., 913 (1981).

23. J. A. Krogh, US 4,500,726 (1984).

24. R. A. Sawicki, Tetrahedr. Lett., 23, 2249 (1982).

25. B. Zaldman, Y. Sasson and R. Neumann, Ind. Eng. Chem. Res. Dev., 24, 390 (1985).

26. JP 84, 112, 839 (1984); Chem. Abstr., 102, 61952H (1984).

27. G. Soula, J. Org. Chem., 50, 3717 (1985).

28. E. O'Neil and J. W. Verbicky, Jr., Eur. Pat. App1. EP 141,692 (1985), Chem. Abstr., 103, 195993b (1985).

29. D. J. Brunelle, Eur. Pat. App1. EP 142,835 (1985); Chem. Abstr., 103, 196007 (1985).

30. Private Communication from M. Burzminski, $2 / 86$.

31. D. J. Brune1le and D. A. Singleton, Tetrahedr. Lett., 25, 3383 (1984).

32. J. Barry, et. a1., Synth., 40 (1985).

33. B. R. Cho and S. D. Park, Bu11. Korean Chem. Soc., 5, 126 (1984).

34. E. Angeletti, et. al., Br. Polym. J., 16, 219 (1984).

35. E. Angeletti, P. Tundo and P. Venturello, Ger. Offen DE 3,334,876 (1984); Chem. Abstr., 101, 191158U (1984).

36. idem.9 J. Chem. Soc., Perkins Trans., 1, 993 (1982).

37. idem., J. Org. Chem., 48, 4106 (1983).

38. idem., J. Chem. Soc., Chem. Commun., 269 (1983).

39. T. L. Evans, Synth. Commun, 14, 435 (1984).

40. Y. Kimura and S. L. Regen, J. Org. Chem., 48, 1533 (1983).

41. S. L. Regen. J. Am. Chem. Soc., 99, 3838 (1977).

42. W. T. Ford, Adv. Polym. Sci., 55, 49 (1984).

43. W. T. Ford, Polym. Sci.\&Tech., 24, 201 (1984).

44. W. M. Mackenzie and D. C. Sherrington, Polymer, 22, 431 (1981).

45. J. Kelly, et. al., Polymer, 23, 1159 (1982).

46. R. Sawicki, Tetrahedr. Lett., 23, 2249 (1982).

47. P. Tundo, P. Venturello and E. Angeletti, J. Am. Chem. Soc., 104, 6551 (1982).

48. F. L. Cook and R. W. Brooker, Polym. Prepr., 23, 149 (1982).

49. D. C. Sherrington, Macromol. Chem., 3, 303 (1984).

50. Y. Imai, Chem. Abstr., 102, 79334T (1984).

51. L. J. Mathias, J. Macrom. Sci. - Chem., A-15, 853 (1981).

52. J. K. Rasmussen and H. K. Howe11, Polym. Sci. Tech., 24, 105 (1984).

53. D. N. Thanh and S. Boileau, Polym. Sci. Tech., 24, 59 (1984).

54. JP 82-73,022 (1982); Chem. Abstr., 97, 5137553 (1982).

55. JP $\overline{82}-21,419$ (1982); Chem. Abstr., $\overline{96}, 218447$ e (1982).

56. N. Seiichi, Eur. Pat. App1. EP 97, $8 \overline{90}$ (1984); Chem. Abstr., 100, 192570P (1984).

57. D. Shaffer and V. Percec, J. Polym. Sci., Polym. Lett. Ed., 23, 185 (1985).

58. J. M. Frechet, Polym. Sci. Tech., 24, 1 (1984).

59. T. Iizaw, et. al., Macromol., 17, 992 (1984).

60. T. Nishikubo, et. a1., Makromo1. Chem. Rapid Commun., 1, 765 (1980).

61. P. Hodge and J. Waterhouse, Polymer, 22, 1153 (1981).

62. A. S. Gozdz, Polym. Bul1., 5,591 (1981).

63. H. Kise and S. Hisayuki, Makromol. Chem., 5, 759 (1984).

64. A. S. Gozdz, ibid, 2, $443(1981)$.

65. F. F. He and H. Kise, Polym. Chem. Ed., 21, 1729 (1983).

66. JP 83-65,701 (1983), Chem. Abstr., 99, 213940N (1983).

67. T. Nishikubo, et. al., Makromol. Chem. Rapid Commun., 3, 617 (1982).

68. H. Kise and H. Ogata, Polym. Chem. Ed., 21, 3443 (1983).

69. A. Nkansah and G. Levin, Polym. Sci. Tech., 21, 109 (1983).

70. J. K. Rasmussen and H. K. Smith II, J. Am. Chem. Soc., 103, 730 (1981); idem, Makromol. Chem., 182, 701 (1981); J. K. Rasmussen, et. a1., J. Am. Chem. Soc., $105,6845(1983)$.

71. J. K. Rasmussen, US 4, 326,049 (1982).

72. J. K. Rasmussen, and H. K. Smith, II, Polym. Sci. Tech., 24, 105 (1984).

73. H. Jaykrishnan and D. D. Shah, J. Polym. Sci., Polym. Chem.Ed., 21, 3201 (1983).

74. JP 83-154,561 (1983); Chem.Abstr., 100, 120891W (1983).

75. F. Montanari, M. Pelosi and F. Rolla, Chem. Ind., 412 (1982).

76. R. Handte and J. H. Nestler, Ger. Offen. 2,939,056 (1981); Chem. Abstr., 95, 80463C (1982).

77. F. Montanari and F. Rolla, J. Org. Chem., 48, 604 (1983).

77A. D. J. Brune1le, ibid, 49, 1309 (1984).

78. D. J. Milner, Synth. Commun., 15, 479 (1985).

79. G. Soula, J. Org. Chem., 50, 3717 (1985).

80. M. Halpern, Y. Sasson and M. Rabinovitz, J. Org. Chem., 49, 2011 (1984).

81. I. M. Rostomyon, et. al., Arm. Khim. Zh., 37, 719 (1984); Chem. Abstr., 102, 149822B (1984).

82. E. M. Asatryan, ibid, 36, 644 (1983); Chem. Abstr., 100, 35554U (1983). 
83. H. Marschner, et, al., Ger. DD 209,183 (1984); Chem. Abstr., 102, 5683J (1984).

84. JP 81-133,227 (1981); Chem. Abstr., 96, 51960C (1981).

85. $\overline{\mathrm{JP}} \overline{81}-133,228$ (1981); Chem. Abstr., $\overline{96}, 51961 \mathrm{D} \mathrm{1981).}$

86. JP $\overline{81}-118,040$ (1981); Chem. Abstr., 96, 51824M (1981).

87. H. J. Krause, Ger. Offen 2,295,521 (1981); Chem. Abstr., 94, 174341T (1981).

88. T. Nishikubo, et. al., Tetrahedr. Lett., 22, 3873 (1981).

89. J. L. Charlton, V. A. Sayeed and G. N. Lypka, Synth. Commun., 11, 931 (1981).

90. H. Kise, J. Polym. Sci., Polym. Chem. Ed., 20, 3189 (1982).

91. D. G. Lee, in Oxidation in Organic Chemistry, Part D, , Academic Press, NY, 147 (1982).

92. E. Schroetter, H. Niedrich and H. Schick, Pharmazie, 39, 155 (1984).

93. G. A. Lee and H. H. Freedman, Tetrahed. Lett., 1641 (1976).

94. F. Ishii and K. Kishi, Synth., 706 (1980).

95. JP 84-05,175 (1984); Chem. Abstr., 101, 7016X (1984).

96. M. E. Brokke and W. L. Magee, Jr., Eur. Pat. App1. EP 140,454 (1985); Chem. Abstr., 103, 123014K (1985).

97. S. Abromovici, R. Neumann and Y. Sasson, J. Mo1. Catal., 29, 291 (1985).

98. L. Horner and J. Gerhard, Phosp. Sulfur, 22, 5 (1985).

99. S. Abromovici and Y. Sasson, J. Mol. Catal., 29, 299 (1985).

100. T. Ido, et. a1., Kagaku Kogaku Ronbunshu, 9 , 58 (1983), ibid, 10, 287 (1984). Chem. Abstr., 98, 125171M (1983); 101, 90171N (1984).

101. H. Alper, Adv. Organomet. Chem., 19, 183 (1981).

102. H. Alper, Fundam. Res. Homogeneous Catal., 4, 79 (1984).

103. G. C. Tustin and R. T. Hembre, J. Org. Chem., 49, 1761 (1984).

104. Fr. Demande FR 2,498,594 (1982); Chem. Abstr., 98, 34264C 1982).

105. A..E. Kalardzhyan, et. a1., Arm. Khim. Zh., 35, 402 (1982); Chem. Abstr., 97, 21546212 1982).

106. R. A. Sawicki, US 4,474,704 (1984).

107. W. M. Kruse, Eur. Pat. Appl. EP 92,998 (1983); Chem. Abstr., 100, $103815 \mathrm{G}$ (1983).

108. T-L Su, R. S. Klein and J. L. Fox, J. Org. Chem., 46, 17901981$)$.

109. S. Koto, et, al., Bull Chem. Soc. Jpn., 55, 2995 (1982).

110. J. Bogusiak and W. Szeja, Carbohydr. Res., 141, 165 (1985).

111. D. Dess, et. a1., Synthesis, 883 (1981).

112. D. Klemm, G. Geschwend and M. Hartmann, Angew. Makromo1. Chem,, 126, 59 (1984).

113. W. H. Daly, et, al., Polym. Sci. Tech., 24, 45 (1984).

114. V. F. Dolling, P. Davis and E. J. Grabowski, J. Am. Chem. Soc., 106, 446 (1984); Eur. Pat. App1. EP 121,872 (1984).

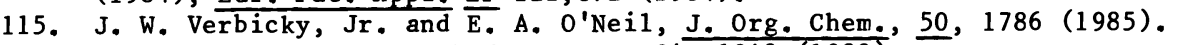

116. J. P. Mazaleyrat, Tetrahedr. Lett., 24, 1243 (1983).

117. S. Colonna and R. Annunziata, Afinidad, 38, 501 (1981); J. Sebastian, et. al., J. Chem. Soc., Perkins I, 574 (1981).

118. E. Chiellini, R. Solaro and S. D'Antone, Polym. Sci. Tech., 24, 227 (1984).

119. Y. Kawakami and Y. Yamashita, ibid, 263.

120. S. D'Antone, et. a1.; Chem. Abstr., 101, 561472 (1983).

121. J. Ke11y and D. C. Sherrington, Polymer, 25, 1499 (1984); J. M. Frechet, J. Kelly and D. C. Sherrington, ibid, 1491.

122. L. Lindblom and M. Elander, Pharm. Tech, , 1 (1980).

123. B. Pelars and R. Ruman, Chem. Abstr., 94, 209043B (1980).

124. J. Reisch, H. Dharmartne and W. Ranjith, Arch. Pharm., 318, 382 (1985).

125. I. Gozlan, et, al., J. Heterocyc1. Chem., 19, 1569 (1982).

126. V. Gomez-Parra, et. a1., Arch. Pharm,, 317, 183 (1984).

127. S. J. Schmolka and H. Zimmer, Synthesis, 29, 1984).

128. J. Reisch, H. Dharmartne and W. Ranjith, Z. Naturforsch.B, 40B, 636 (1985).

129. J. G. Thorpe and R. Peel, Eur. Pat. App1. EP 142,979; Chem. Abstr. 103, 214992U (1983).

130. M. Biedrzycki, et. a1., Eur. Pat. App1. EP 119,431; Chem. Abstr., 102, 96002A (1984).

131. P. Moe11mann, et. al., Ger. DD 205,681 (1984); Chem.Abstr., 101, 110619V (1984).

132. JP 84-53,491 (1984); Chem. Abstr., 101, 110638A (1984).

133. M. Hedayatullah, C. R. Acad. Sci. Ser., 2,300, 743 (1985).

134. F. Seela and S. Menkhoff, Liebigs Ann. Chem., 1360 (1985).

135. E. Essassi, et. al., Hereocycles, 23, 799 (1985).

136. M. J. O'Donneli, J. M. Boniece and S. E. Earp, Tetrahed. Lett., 2641 (1978).

137. M. J. O'Donne11, et. al., Synthesis, 127 (1984).

138. ibid, 313.

139. JP 82-193,433; Chem. Abstr. 98 216001Y (1982); JP 82-118,547; Chem. Abstr., 98, $\overline{17051 P}(1982)$.

140. V. Dryanska, et. a1., Izv. Khim., 15, 203 (1982); Chem. Abstr., 98, 215240N (1982).

141. JP 82-95,964 (1982); Chem. Abstr., 98, 4555F (1982).

142. B, Krawczynska, et. a1., Pol. P1. 120,083 ; Chem. Abstr., 99, 1758818u (1983). 
143. R. C. Floc'h, et, al., J. Chem. Res. Synop., 318 (1981).

144. A. Reinink and R. A. She1don, US 4,175,094 (1979); D. A. Wood, US 4,409,150 (1983).

145. H. Yoshikawa, T. Shono and M. Eto, Chem. Abstr., 103, 87984R (1984).

146. J. P. Chupp, US 4, 351,667 (1982).

147. N. A. Cortese and W. H. Gastrock, US 4,532,629 (1984).

148. J. Mueller, et. a1., Ger. Offen. $\overline{\mathrm{DE}}$ 3,341,306 (1985); Chem. Abstr., 103, $178161 \mathrm{M}$ (1985).

149. J. M. Renga and P.-C.Wang, Synth. Commun., 14, 69 (1984); US 4,349,487 (1982).

150. ibid, 77: US 4,410,718 (1983).

151. JP 83-24,578 (1983); Chem. Abstr. 98, 216183H (1983).

152. JP $\frac{83}{83}-208,282$ (1983); Chem. Abstr., 100, 103157U (1983). JP $85-97,971$ (1985); Chem. Abstr., 103, 123340P (1985).

152a. G. Mouzin, H. Cousse and J. P. Riew, Fr. Demande FR 2,479,822; Chem. Abstr. 96, 142681D (1981). idem, Synthesis, 117 (1983).

153. A. Aserin, N. Garti and Y Sasson, Ind. Eng. Chem. Prod. Res. Dev., 23, 452 (1984).

154. J. Chupp and T. E. Neumann, Eur. Pat. App1. EP 150,169 (1985); Chem. Abstr. $103,214958 \mathrm{~N}$ (1985).

155. P. P. Nicholas, Rubber Chem. Technol., 55, 1499 (1982).

156. D. J. Brunnelle, Chemosphere, 12, 167 (1983).

157. D. J. Brunnelle and D. A. Singleton, ibid, 183.

158. V. K. Krishnakumar and M. Sharma, Ind. Eng. Chem. Proc. Des. Dev., 23, 410 (1986).

159. T. L. Evans, Eur. Pat. App1. EP 108,682 (1984); Chem. Abstr., 101, 110527P (1984).

160. R. Liotta, K. Rose and E. Hippo, J. Org. Chem., 46, 277 (1981). 